\title{
Erratum to: More Comprehensive Forensic Genetic Marker Analyses for Accurate Human Remains Identification Using Massively Parallel DNA Sequencing
}

Angie D. Ambers ${ }^{1 *}$, Jennifer D. Churchill', Jonathan L. King ${ }^{1}$, Monika Stoljarova ${ }^{1,2}$, Harrell Gill-King ${ }^{3}$, Mourad Assidi ${ }^{4}$, Muhammad Abu-Elmagd ${ }^{4}$, Abdelbaset Buhmeida ${ }^{4}$, Mohammed Al-Qahtani ${ }^{4}$ and Bruce Budowle ${ }^{1,4^{*}}$

\section{Erratum}

This article [1] unfortunately published with an author deleted in the author list. The correct author list is presented above.

The author list was previously incorrectly presented as:

Angie D. Ambers ${ }^{1^{*}}$, Jennifer D. Churchill ${ }^{1}$, Jonathan L. King $^{1}$, Monika Stoljarova ${ }^{1,2}$, Harrell Gill-King ${ }^{3}$, Mourad Assidi $^{4}$, Muhammad Abu-Elmagd ${ }^{4}$, Abdelbaset Buhmeida ${ }^{4}$ and Bruce Budowle ${ }^{1,4^{*}}$

${ }^{1}$ Institute of Applied Genetics, Department of Molecular and Medical Genetics, University of North, Texas Health Science Center, 3500 Camp Bowie Boulevard, Fort Worth, TX, USA. ${ }^{2}$ Institute of Gene Technology, Department of Molecular Diagnostics, Tallinn University of Technology, Akadeemia tee 15A-604, Tallinn 12618, Estonia. ${ }^{3}$ Department of Biological Sciences, Laboratory of Forensic Anthropology, Center for Human Identification, University of North Texas, 1511 W. Sycamore, Denton, TX, USA. ${ }^{4}$ Center of Excellence in Genomic Medicine Research (CEGMR), King Abdulaziz University, Jeddah, Saudi Arabia.

\section{Author details}

${ }^{1}$ Institute of Applied Genetics, Department of Molecular and Medical Genetics, University of North Texas Health Science Center, 3500 Camp Bowie Boulevard, Fort Worth, Texas, USA. ${ }^{2}$ Institute of Gene Technology, Department of Molecular Diagnostics, Tallinn University of Technology, Akadeemia tee 15A-604, Tallinn 12618, Estonia. ${ }^{3}$ Laboratory of Forensic Anthropology, Center for Human Identification, University of North Texas, Department of Biological Sciences, 1511 W. Sycamore, Denton, Texas, USA. ${ }^{4}$ Center of Excellence in Genomic Medicine Research (CEGMR), King Abdulaziz University, Jeddah, Saudi Arabia.
Received: 8 March 2017 Accepted: 8 March 2017

Published online: 20 April 2017

\section{References}

1. Ambers AD, Churchill JD, King JL, Stoljarova M, Gill-King H, Assidi M, Abu-Elmagd M, Buhmeida A, Al-Qahtani M, Budowle B. More Comprehensive Forensic Genetic Marker Analyses for Accurate Human Remains Identification Using Massively Parallel DNA Sequencing. BMC Genomics. 2016;17 Suppl 9:750.

*Correspondence: angie.ambers2@unthsc.edu; bruce.budowle@unthsc.edu ${ }^{1}$ Institute of Applied Genetics, Department of Molecular and Medical Genetics, University of North Texas Health Science Center, 3500 Camp Bowie Boulevard, Fort Worth, Texas, USA 